\title{
Integrated Evaluation Framework for Irrigation Development in South India
}

\author{
Holly M. Lafontaine, B.A.Sc. \\ Master's Candidate-Civil \\ Engineering \\ University of Windsor \\ lafont1@uwindsor.ca
}

\author{
Tirupati Bolisetti \\ Assistant Professor \\ Civil and Environmental Eng. \\ University of Windsor \\ tirupati@uwindsor.ca
}

\author{
R. Balasubramaniam \\ Executive Director, GRAAM, \\ Swami Vivekananda Youth \\ Movement, Mysore, India \\ drrbalu@gmail.com
}

\begin{abstract}
The term engineer is no longer restricted to a technology developer pushing the envelope of productivity, innovation, and efficiency. Instead, engineers are now expected to address global issues while ensuring socially, economically, and environmentally sustainable solutions. In order to meet this demand, engineers need to move away from traditional technology focused development approaches and pursue the role of a 'global engineer' with the ability to apply multi-disciplinary skills, understand complex socio-econo-political interactions with technology, and work in cross-cultural environments.

This research investigates the multi-disciplinary needs of the engineering community in the development sector, the skills and knowledge required to effectively address limitations of data availability and access, considers social and economical indicators of success, as well as address the engineer operating in a different culture and language. An irrigation scheme in south India was evaluated with social, economical, and technical measurement indicators instead of depending upon a solely technical approach. This approach led to the discovery of more factors influencing the success and failure of the irrigation scheme. With a more holistic evaluation, the potential for a more appropriate design for users; a better strategy for implementers; and the introduction of improved monitoring mechanisms for donors are made possible.
\end{abstract}

\section{Introduction}

The term engineer is no longer restricted to a technology developer pushing the envelope of productivity, innovation, and efficiency. Instead, engineers are now employing their technical skills within broader systems and environments, which require multi-disciplinary approaches and crosscultural interactions. Over the last decade, much effort has been placed on investigating what role western engineers should take in our global society and what skills and attributes will be needed for this successful integration. The Canadian Engineering Accreditation Board [1] identifies that engineers need to possess a broad range of attributes that allow for appropriate design, effective communication, multi-disciplinary team work, and the ability to understand and analyze the social and environmental implications of engineering work. According to Berndt [2], engineering students are motivated to work on 'authentic, complex' projects that reflect real-world challenges and that promote communication with socio-political actors and engagement with community. The demand and desire for engineers to contribute to the 'big picture' can be seen through the successful introduction of an Entrepreneurial Design for Extreme Affordability program at Stanford [3], the Engineering for Developing Communities program at the University of Colorado [4] and the integration of a Technology and Development course and the University of British Columbia [5].

Even corporations are recognizing the importance of social responsibility and environmental stewardship since the Harvard Business Review [6] classified sustainability as an 'emerging megatrend' where environmental issues are beginning to dictate business success. There is no doubt that the dynamics of engineering are changing and that the next generation of engineers will be facing challenges in a broader global arena. This will require a deeper understanding of the geo-political and socio-economical implications of engineering decision making. To meet the demand for this emerging 'global engineer', there is a need to define the specific multi-disciplinary skills needed, as well as define the applicability of various frameworks and tools from business or social science disciplines that facilitate this emergence. This paper presents the expectations of the 'global engineer' from the authors' experience in Southern India as well as highlights applicable frameworks and tools that facilitated: 1) the western engineer's ability to effectively operate in Southern India and 2) the development of a multifaceted evaluation tool for small-scale irrigation technology in Southern India. 


\section{Scope of the Study}

The purpose of the study is to develop an integrated monitoring and evaluation framework for international development projects that promotes grassroots learning to influence organizational and political change. In order to examine the impact of government schemes, technology integration, and current monitoring systems, a study was selected to evaluate the efficacy of an irrigation scheme in Southern India. The University of Windsor in collaboration with a local non-governmental organization (NGO) in Southern India is developing an evaluation framework to be piloted and potentially implemented throughout the State of Karnataka, India. The irrigation scheme provides 'below poverty line' farmers with a free borehole and pump-set to be used for irrigating cropland of up to 8 acres. The challenge for the engineer and the NGO is to work together to develop measurement indicators that will evaluate the project from both a socio-economical perspective as well as a technical engineering perspective. The goal is to examine how the engineer can incorporate a social and cultural sensitivity into traditional engineering evaluation methods for water management and work directly with social experts as an integral component of the project design. This will create a holistic understanding of the irrigation technology in the big picture' and allow for more appropriate recommendations for improvement.

\section{Traditional Role of an Engineer}

Traditionally water management has been studied through the examination of rainfall patterns [7], and watershed management [8] to ensure the effective use of water resources and control of water quality. Brugere and Lingard [9] describes performance indicators for irrigation systems and state that: "From engineering and agricultural perspectives, these include: water delivery efficiency, water balance ratios, water conveyance ratios, sustainability of irrigated areas, and irrigated agriculture performance, which take into account production per unit of water supplied." These types of indicators provide the engineer with a deep understanding of the functionality of an irrigation system as well as the ability to diagnose technical inefficiencies.

The Food and Agriculture Organization of the United Nations (FAO) [10] describes that major water losses in furrow irrigation are due to surface runoff and deep percolation where water can no longer be captured by plant roots. To mitigate these losses, engineers and agriculturalists have discovered basin irrigation, and land leveling techniques. Pistor [11] examined the importance of irrigation scheduling and determined the magnitude and frequency of irrigations to maximize crop yield. Even micro-irrigation systems have been explored as cost-effective solutions for India. Sivanappan [12] determined that drip irrigation can perform at $90 \%$ efficiency and save anywhere from $40-80 \%$ of water.

Engineers have been able to examine technological systems, quickly recognize system flaws, and design efficient, durable, and cost-effective solutions. However, there is still a gap between the technology and science developed and the ability of this technology to meet the needs of our global society. Pistor [11] examined that without a full understanding of irrigation scheduling, over irrigating can cause as much crop damage as a minor drought. Even the sustainability of boreholes and pump-sets in India has been questioned by UNICEF [13]. There is a need for engineering to move beyond the design and development of technology alone but instead examine the integration of technology into our global society.

\section{Non-Traditional Role of an Engineer}

In The Critical Villager, Eric Dudley [14] addresses the gap of failed technological solutions in international development by specifying that "[w]ithout an understanding of how and why people change, knowledge of the mechanics and high finance of technical aid will be of little use." Brugere and Lingard [9] suggest that a focus on water as the 'sole' agricultural input is not sufficient if the effect of fertilizer, pesticide, and agricultural labour are ignored. Although engineers are equipped with the technical ability to address global issues, it is apparent that technology alone will not provide effective solutions. Chan and Fishbein [15] describe attributes of a 'global engineer' that provide a foundation for this integrated development perspective. They suggest that a 'global engineer' has the ability to recognize the social, economical, and environmental implications of engineering, to communicate across language and cultural differences, to work in an interdisciplinary manner, and is knowledgeable on global issues, emerging trends and has the ability to respond to these issues and trends. This shift has already taken place in India where Shagufta [8] suggests a participatory watershed management approach that ensures "sustainability of the ecological, economic and social exchanges" in the Amachal watershed, India. His focus on education has provided a common definition of watershed management for local citizens. Further, his efforts to promote community participation have ensured the sustainable management of local water systems. Shagufta's model is one example of the 
successful shift in the engineering profession to address global issues in a holistic manner.

\subsection{Non-traditional role of the western engineer in Southern India}

In order for the engineer to operate effectively in Southern India, a broad understanding of multiple disciplines was required. Highlighted below are some of the project specific expectations of the western engineer that diverged from the traditional role. Further, frameworks and tools are provided that assisted the engineer in meeting these expectations.

The western engineer:

- Facilitated meetings with all stakeholders (donor, NGO, technical experts, and social scientists) to develop clear objectives for the evaluation study that met all of the stakeholders' needs.

- Facilitated a discussion with all stakeholders on the potential pathways to achieve the desired technical and non-technical objectives of the study.

- Identified opportunities and challenges associated with the local context, culture, time, resources etc.

- Developed a project implementation plan that reflected the stakeholder discussions.

- Managed interactions and communications between the donor, NGO, technical experts, social scientists and the University of Windsor.

- Participated in the design of the field staff training program and co-facilitated the training program.

- Participated in the design of the evaluation tool which required the creation of culturally appropriate interview questions to understand the farmer's interaction with the irrigation technology.

- Operated under different cultural norms and organizational structures.

\subsection{Assisting frameworks and tools}

\subsubsection{Business frameworks and tools}

\subsubsection{Identifying organizational cultures}

It takes time for a western engineer to understand the culture of an international partner organization. Adapted from the KEYSTEP Growth \& Finance workshop Business Development \& Entrepreneurship: How To Execute Business Plans For Success [16], Figure 1 displays the different types of organizational cultures. In the workshop Kallai, explains the importance of understanding and developing an appropriate organizational culture that meets the needs of the business. Having an understanding of the different types of organizational cultures provided a faster culture recognition and integration for the engineer.

\begin{tabular}{|l|l|}
\hline Political, Autocratic: & Entrepreneurial: \\
-Visionary leader & -Highly energetic team \\
-Most decisions are & -Trial and failure is \\
made at the top & tolerated \\
-Managers compete for & -Definition of roles and \\
the attention of the & responsibilities may be \\
leader & lacking \\
& -Communications and \\
& planning is ad hoc \\
\hline Bureaucratic: & High-Performance \\
-All responsibilities are & Team: \\
well defined & -Well defined roles, \\
-All about paper trail & responsibilities and \\
-Decision making must & objectives \\
be at a pre-determined & -Collaboration is key and \\
level in the proper form & reinforced among team \\
& members \\
& -Significant effort in \\
& planning and coordinating \\
& activities \\
& -Open, regular \\
communications
\end{tabular}

Figure 1: Organizational cultures, adapted from KEYSTEP Growth \& Finance [16]

Further, Schein [17] describes culture as a series of "shared learning experiences that lead...to shared...basic assumptions." Although the culture of the organization has little effect on the technical study, the engineer needed to develop mutual trust with team members and understand the differences in communication amongst men and women, between managerial and field staff, as well as learn common phrases to interact more smoothly with local citizens. The engineer took time to participate in local traditions, spent hours visiting farmers in the field, and learned a bit of the local language.

\subsubsection{Defining product requirements}

Through KEYSTEP Growth \& Finance, Kallai [16] teaches the importance of understanding the different perspectives of various stakeholders on a single product. In an effort to reconcile differences between the marketer, customer, engineer, and manufacturer, he explains the 'must haves', 'nice to haves', and the 'will not do' concept. When adapted to project design, 
this simple approach of depicting different perspectives, created a mechanism for the engineer to consider and organize various opinions from a variety of stakeholders and incorporate them into the evaluation tool.

\subsubsection{Supply chain analysis}

Adapted from Engineers Without Borders Canada Agricultural Value Chains Program [18], supply chain analysis provided the engineer with a tool to look beyond the design and development of the technology but to see how it interacts in the broader environment that the irrigation pump was implemented in. This framework played a major role in discussing other limiting factors to agricultural success such as access to fertilizers and pesticides, farmer's distance from local, regional, or national markets, the pattern of irrigation pump usage, animal attacks on cropland, and the local access to pump maintenance or repair. Similar concepts are also represented in the traditional engineering framework of Life Cycle Analysis; however, supply chain analysis places an emphasis on social and economical factors versus environmental impact.

\subsubsection{Social science frameworks and tools}

\subsubsection{Impact chain}

This logic framework in Figure 2 from Engineers Without Borders' Orange Book of Change [19], connects intended project impacts to the necessary activities and inputs required to achieve those impacts. This provided the engineer with a project planning tool that communicated goals and plans clearly and concisely to stakeholders from different educational backgrounds.

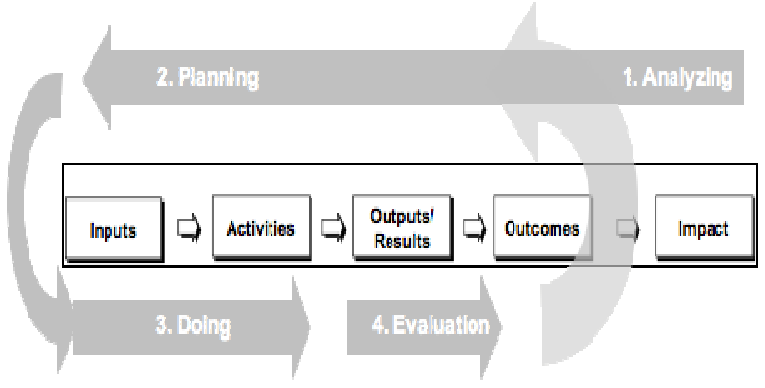

Figure 2: Impact chain, adapted from Engineers Without Borders' Orange Book of Change [19]

\subsubsection{Interview design and field interviewing techniques}

The availability of accurate and reliable data for the irrigation system was limited. Data that was accurate was not always easily accessible or was written in the local language. Therefore, the ability to interact with farmers, local citizens, and field staff was crucial to obtaining pertinent information. These interviewing techniques adapted from Asking Questions The Definitive Guide to Questionnaire Design For Market Research, Political Polls, and Social and Health Questionnaires [20] provided the engineer with an understanding of bias and variability, helped define threatening versus non-threatening questions in relation to the specific cultural context, evaluated the effectiveness of open-ended versus close-ended questions, and displayed ways to structure questions that would achieve high accuracy and reliability.

\subsubsection{Education frameworks and tools}

\subsubsection{Discussion facilitation}

The Peer to Peer An Engineers Without Borders Facilitator Guide [21] provides a broad range of tools and techniques from discovering personality type, group dynamics, and learning styles to managing group behaviours, structuring a discussion, and obtaining feedback. This tool provided a strong foundation for the engineer to facilitate meetings and project discussions with many stakeholders. Further, these techniques we applied to the creation and cofacilitation of field staff training.

Further facilitation practice and skills were obtained in a Leading Effective Discussions workshop through the Center for Teaching and Learning at the University of Windsor [22]. This workshop identified criteria for developing engaging questions, and discussed different activities and techniques that could be employed in the classroom.

\section{Outcomes}

Using the multi-disciplinary approach, the interview tool that was developed by the engineer and the nonengineers reflected a much broader range of categories. The tool was separated into 5 main sections: General Information, Agriculture and Technology, Economic Information, Education, and Irrigation Scheme Overview. Through this process the engineer was able to map the borehole locations and obtain functionality specific data but more importantly was able to relate this data to the big picture of irrigation development. One question from each section and the associated benefits for the analysis are highlighted below in Table 1 . These represent just a 
few examples of the insights obtained from the multidisciplinary approach.

Table 1: Benefits of the integrated evaluation approach

\begin{tabular}{|c|c|}
\hline $\begin{array}{l}\text { The Interview } \\
\text { Question }\end{array}$ & The Benefit to the Study \\
\hline $\begin{array}{l}\text { How do you } \\
\text { determine when } \\
\text { each person uses the } \\
\text { borehole and the } \\
\text { quantity of water } \\
\text { each person uses? }\end{array}$ & $\begin{array}{l}\text { This question examined the } \\
\text { shared use of group scheme } \\
\text { irrigation systems. This } \\
\text { provided insight into the } \\
\text { shared management of the } \\
\text { irrigation system. Further, } \\
\text { grassroots water sharing } \\
\text { techniques were discovered. }\end{array}$ \\
\hline $\begin{array}{l}\text { Did you grow } \\
\text { different crops } \\
\text { before receiving the } \\
\text { borehole and pump- } \\
\text { set? Why change? }\end{array}$ & $\begin{array}{l}\text { This question examined the } \\
\text { behavior change of the farmer } \\
\text { due to the introduction of } \\
\text { technology. The introduction } \\
\text { of the technology alone may } \\
\text { have influenced farmers to } \\
\text { change cropping patterns } \\
\text { without a full consideration of } \\
\text { market access, or water } \\
\text { availability in the area. This } \\
\text { provided an opportunity to } \\
\text { examine typical crop change } \\
\text { behaviours and potential } \\
\text { motivations for the change. }\end{array}$ \\
\hline $\begin{array}{l}\text { Have you purchased } \\
\text { any new assets after } \\
\text { becoming an } \\
\text { irrigation scheme } \\
\text { participant? For } \\
\text { example, land, } \\
\text { livestock, gold etc. } \\
\text { and what was the } \\
\text { cost? }\end{array}$ & $\begin{array}{l}\text { This questioned allowed the } \\
\text { team to track the purchasing } \\
\text { power of the farmers involved } \\
\text { after they started using the } \\
\text { irrigation system. Further, the } \\
\text { ability to pay for pump } \\
\text { maintenance or invest in } \\
\text { additional technology was } \\
\text { discovered. }\end{array}$ \\
\hline $\begin{array}{l}\text { Do any of the } \\
\text { children in the house } \\
\text { attend school or } \\
\text { college? }\end{array}$ & $\begin{array}{l}\text { This question examined the } \\
\text { number of children in each } \\
\text { house that were attending } \\
\text { school. In the follow-up } \\
\text { question reasons for not } \\
\text { attending were discovered. } \\
\text { This linked the irrigation } \\
\text { technology to education in the } \\
\text { poverty cycle. }\end{array}$ \\
\hline $\begin{array}{l}\text { On a scale of } 1 \text { to } \\
100 \text { how would you } \\
\text { rate the overall } \\
\text { success of your } \\
\text { irrigation scheme? }\end{array}$ & $\begin{array}{l}\text { When compared to water } \\
\text { availability, pump operation or } \\
\text { income data, this question } \\
\text { examined the differences or } \\
\text { similarities between that actual } \\
\text { benefit of the technology and } \\
\text { the perceived benefit. }\end{array}$ \\
\hline
\end{tabular}

\section{Conclusion}

As the demand for engineers to address global issues that cross political, economical, and social borders increases, the need for the emerging 'global engineer' will rise. Engineering education has already begun adapting to these new expectations by incorporating international experience and multi-disciplinary courses into curriculum. However, if engineers plan to address international development issues, technology development alone will not produce sustainable solutions. Incorporating business and social science frameworks as integral components of project planning, provides a model that can achieve appropriate, thoughtful, and successful solutions. In Southern India, a multi-disciplinary approach was pursued to develop and interview tool that captured grassroot learnings from a technical and non-technical perspective. This tool connected the irrigation technology to the bigger picture of behavior changes amongst farmers, financial investments, and family educational opportunities.

\section{References}

[1] CEAB "Accreditation criteria and procedure 2010," Canadian Engineering Accreditation Board, 2008, pp. 12-13. [2] A. Berndt, "Sustainability and the Official Community Plan: Integrating Community-Based Research Initiatives into a Standardized Technical Communication Course for Second-Year Engineering Students", Canadian Engineering Education Conference Proceedings, 2010.

[3] Stanford University Institute of Design, Entreprenurial Design for Extreme Affordability, 2010 [Online]. Available: http://extreme.stanford.edu/big_picture/our_vision.html [4] B. Amadei and R. Sandekian, "Model of Integrating Humanitarian Development into Engineering Education", Journal of Professional Issues in Engineering Education and Practice, ASCE, April 2010. pp. 88.

[5] A. Kajenthira and J. Fishbein, "Enhancing Engineers' Contributions to Global Society", Engineering Education Conference Proceedings, 2010.

[6] D. A. Lubin and D. C. Esty, "The Sustainability Imperative", Harvard Business Review, May 2010.

[7] P. Guhathakurta and M. Rajeevan, "Trends in the rainfall pattern over India”, International Journal of Climatology, Royal Meteorological Society, November 2007, pp. 14531469.

[8] C. J. Shagufta, Watershed Management, APH Publishing Corporation, New Delhi, 2010.

[9] C. Brugere and J. Lingard, "Irrigation deficits and farmers' vulnerability in Southern India", Agricultural Systems, Elsevier Science Ltd., 2003, vol. 77, pp. 75-88. [10] Food and Agriculture Organization Land and Water Development Division \& International Institute for Land Reclamation and Improvement, "Irrigation water management training manual no 4: irrigation scheduling", 
Food and Agriculture Organization of the United Nations, Rome, Italy, 1989.

[11] V. Pistor, A Climatological Approach to Irrigation Scheduling, University of Windsor, 1967.

[12] R. K. Sivanappan, "Prospects of micro-irrigation in India", Irrigation and Drainage Systems, Kluwer Academic Publishers, Netherlands, 1994, vol. 8, pp. 49-58.

[13] UNICEF, "Village water supplies", [Online]. Available: http://www.unicef.org/sowc96/hpump.htm

[14] E. Dudley, The Critical Villager, Routledge, London, 1993.

[15] A. D. Chan and J. Fishbein, "A global engineer for the global community", The Journal of Policy Engagement, 2009, vol. 1, pp. 8 .

[16] P. Kallai, Business Development \& Entrepreneurship: How To Execute Business Plans For Success, KEYSTEP Growth \& Finance, 2006.

[17] E. H. Schein, Organizational Culture and Leadership, John Wiley \& Sons, Inc., San Francisco, 2004.
[18] Engineers Without Borders Canada, Access to Markets: Linking farmers with business in Southern Africa, [Online]. Available:

http://www.ewb.ca/en/whatwedo/overseas/projects/marketac cess_zambia.html

[19] Engineers Without Borders Canada, Orange Book of Change, 2009, [Online]. Available:

http://wiki.ewb.ca/en/Impact_chain___Pro

[20] N. Bradburn, S. Sudman and B. Wansink, Asking Questions The Definitive Guide to Questionnaire Design For Market Research, Political Polls, and Social and Health Questionnaires, John Wiley \& Sons Inc., San Francisco, 2004.

[21] Engineers Without Borders Canada, Peer to Peer An Engineers Without Borders Facilitator Guide, [Online]. Available: http://chapters.ewb.ca/pages/memberlearning/personal-and-chapter-learning_-leadership_-andfacilitation/the-facilitators-guide.pdf

[22] Centre for Teaching and Learning, University of Windsor, Leading Effective Discussions, 2011 